\title{
Biometric Infrastructures and the Indian Public Distribution System
}

Silvia Masiero

\section{CpenEdition}

\section{Journals}

Electronic version

URL: http://journals.openedition.org/samaj/6459

DOI: $10.4000 /$ samaj.6459

ISSN: 1960-6060

Publisher

Association pour la recherche sur l'Asie du Sud (ARAS)

Electronic reference

Silvia Masiero, «Biometric Infrastructures and the Indian Public Distribution System », South Asia Multidisciplinary Academic Journal [Online], 23 | 2020, Online since 27 April 2020, connection on 16 September 2020. URL : http://journals.openedition.org/samaj/6459; DOI : https://doi.org/10.4000/ samaj.6459

This text was automatically generated on 16 September 2020

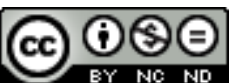

This work is licensed under a Creative Commons Attribution-NonCommercial-NoDerivatives 4.0 International License. 


\title{
Biometric Infrastructures and the Indian Public Distribution System
}

\author{
Silvia Masiero
}

\section{Introduction}

1 The Public Distribution System (PDS) is the main food security program in India, based on the distribution of primary necessity goods at subsidized prices. ${ }^{1}$ Prompted by the severe food shortages experienced in pre-independence India, the PDS is a nationwide scheme articulated in two parts: firstly, essential commodities (primarily rice, wheat, sugar, and kerosene $)^{2}$ are procured by the central government from private producers at below market prices, and secondly, these are redistributed through fair-price shops, most commonly known as ration shops, throughout the nation. Organization of the PDS is divided between the central government, which makes decisions on national food policy and allocates rationed goods to the states, and state administrations, which design and implement distribution schemes at the local level.

2 The nation's dependency on food imports was high in pre-independence times, but significantly reduced following the Green Revolution in the early and mid-1960s. Launched in 1965, the PDS was thus designed as a scheme for internal redistribution of foodgrains, purchased from food-surplus regions and transferred to food-deficit ones at affordable prices. However, one stream of scholarship views the 1990 s as a "lost decade" in the improvement of national living standards, since economic growth was not matched by proportional outcomes in poverty reduction (Sen and Himanshu 2004; Himanshu 2007) ${ }^{3}$ and, as exposed by the latest round of the National Family Health Survey (NFHS-4) conducted in 2015-16, India still struggles with achieving basic goals of health and nutrition.

Over the last two decades, state-level PDS schemes have become increasingly computerized, especially in response to the issues of diversion to the private market that affect the program. The argument supporting end-to-end digitization of antipoverty schemes in the name of greater effectiveness has been applied to the PDS, 
generating local systems that inscribe technology in diverse parts of the program's supply chain. A catalyst for such efforts has emerged in the form of Aadhaar, the nationwide database which assigns a unique biometric and 12-digit identifier to all enrollees. With the passing of the Targeted Delivery of Financial and Other Subsidies Benefits and Services Act-most commonly known as the Aadhaar Bill-in March 2016, the integration of biometric identification into anti-poverty programs was legally ratified and, as of the time of writing, has been introduced in multiple Indian states.

Based on nine-year research on the computerization of the PDS, this paper reflects on the ongoing transformation experienced by the program and its effects through the adoption of the ecosystem constituted by Jan Dhan Yojana, Aadhaar and mobile technologies-the "JAM Trinity"-that proposes to improve access to social benefits for all. Governmental narratives illustrate the proposed transformation, the implementation of a new cash transfer system to eliminate distortions to the economy and prevent diversion. It is argued that, while justified by solid anti-poverty objectives, the biometric transformation of the PDS does not impede exclusion errors, and the transition to the cash transfer system has uncertain effects on recipients' ability to access social protection. Contributing to the debates on coded citizenship and social policy in India, the paper reflects on the transformation that biometric infrastructures induce in the PDS, and considers various measures for achieving greater inclusivity in line with the National Food Security Act (NFSA) legislation.

5 This paper is structured as follows. Following a synopsis of my fieldwork and methodology, I detail the key phases in the history of the PDS, from pre-independence times until the move from a universal to a targeted system in 1997. I then introduce the issue of diversion, and the ways in which successive digital systems have sought to address its shortcomings. The effects of digital transformation are then discussed through insights from my research on Kerala and Karnataka, two states that moved to an Aadhaar-based PDS after a history of back-end digitization. The discussion positions the paper in the debates on coded citizenship and Indian social policy, and reviews some alternatives for tailoring new technologies to ensure a more effective PDS.

\section{Fieldwork and methodology}

6 My interest in the computerization of social protection schemes, of which the Indian PDS is an example, began in 2010 with a preliminary study of the PDS in Kerala. Back then the program was being augmented by a four-module software which facilitated ration card release, allocation of foodgrains, monitoring of ration shops, and provided a web portal through which relations with recipients were to be managed. The introduction of the proposed digital transformation of a large anti-poverty infrastructure raised conceptual and practical issues that triggered my research interest, leading me to investigate the state-level digital PDS in Kerala and its implementation. My PhD fieldwork, conducted in 2011-2012, consisted of 126 interviews with the actors of the Kerala PDS, observation in PDS outlets, and live demonstrations of the system already in operation at the National Informatics Centre (NIC) in charge of the computerization (Masiero 2015, 2017).

7 Initially developed separately from anti-poverty schemes (Nilekani and Shah 2016), over time the biometric infrastructure of Aadhaar became incorporated in the PDS of several states, giving rise to the current, biometrically-enabled authentication system. 
This had implications for the domains of program architecture and recipients' entitlements, which my research intended to reveal. For this reason, working in the state of Karnataka which pioneered a state-level biometric system and then adopted an Aadhaar-based PDS, I conducted two more rounds of fieldwork, respectively in 2014-2015 (on the state-level biometric system) and 2018-2019 (on the Aadhaar-enabled one). This research, published in several works (Masiero and Prakash 2015; Prakash and Masiero 2015; Masiero 2018; Masiero and Das 2019), is complemented by a systematic review of cases of Aadhaar-based PDS in India based on secondary sources and aimed at understanding the diversity of state-level experiences in which my primary findings are contextualized.

8 I adopt a qualitative-interpretive method of enquiry in my research. Interpretive research is premised on the position that our knowledge of reality, rather than an appraisal of a unique and objective truth, is a social construction by human actors (Walsham 2006). This leads the researcher to appraise actors' multiple interpretations of the phenomena of interest, spending time in the field and tracing the history of the subjective images that actors form of the events and processes they encounter. This method, termed a "historiography of images" in my PhD research (Masiero 2014), inspires my data collection and analysis, which is centered on respondent-led accounts of the phenomena under discussion and triangulated with perspectives from other respondents, observation in the field and secondary data according to the core principles of interpretive research (Walsham 2006).

\section{PDS: From Pre-Independence Rationing to Universal Distribution}

9 Mooij (1998) articulates the historical development of the PDS in three phases. In the first phase (1939-1965) the original traits of the food distribution program emerged, while in the second (1965-1990) the scheme operated under a universal form coordinated by the Food Corporation of India (FCI). In the third phase, beginning with the Structural Adjustment Programme of 1991, the PDS became a targeted scheme, reducing subsidies to households above the poverty line (APL) and, in certain states, eliminating APL subsidies altogether.

India depended highly on foreign imports of foodgrain until 1939, when rationing was introduced as an emergency measure in Bombay (Mooij 1998:79). It was from within a scenario of lowered production of foodgrains per capita and high import reliance, in tandem with a cessation of Burmese shipments of rice and wheat after its fall in April 1942, that war erupted (Mooij 1998:80). Entitlement failures, combined with food deficits at the local level, caused between 1.5 and 3 million deaths in the Bengal famine of 1943 (Sen 1981). In his essay on the root causes of famines, Sen illustrates how the colonial machinery and the pursuit of war diverted food away from the needy by prioritizing procurement for the ongoing conflict, precipitating a crisis of entitlements rather than an effective shortage of food (Sen 1981:52-85). ${ }^{4}$

11 As Mooij (1998:80) notes, wartime food-related concerns focused especially on foodgrain prices, revealing the need for an effective mechanism for the centralization of purchase and distribution of foodgrains. At the sixth Price Control Conference (1942) a Food Department was created, defining the core functions of an early-stage distribution system which aimed to regulate prices and curb distributional issues in 
times of war. The Food Department was mandated to buy foodgrains from private producers in provinces in which there was a surplus and allocate them to provinces in which there was a deficit, where they would be sold below market price (Mooij 1998:80). Post-Independence, the Department was maintained under Nehru although these years were again characterized by high reliance on food imports from neighboring countries (Mooij 1998:81-84).

In 1965 the food security system took the shape of the PDS under the management of the newly established FCI. As stated by the Foodgrain Prices Committee, the mandate of the FCI was that of "enabling the government to undertake trading operations, through which it will influence market prices" (Government of India 1968, cited in Mooij 1998:84). The establishment of FCI gave rise to the universal PDS, a shape that the program maintained until the early 1990s. The scheme's operations took over the tasks performed in the 1940s by the Food Department: the FCI bought commodities from private producers, stored them in warehouses across the nation, and redistributed them through Authorized Wholesale Dealers (AWDs) from which ration shops collected goods monthly.

From 1965 to 1990 the amount of foodgrains traded by the FCI increased from 10 to more than 18 million tons, and the number of ration shops in the nation grew to over 350 thousand (Mooij 1998:86). The size of subsidy increased from 0.04 percent of GDP in 1970-1971 to 0.5 percent in 1990-1991 (Ahluwalia 1993). In these first decades of existence, an important strength of the scheme was its network of ration shops which offered a proximity to users, even in remote villages, and was aimed at making the State a visible presence in poorer people's lives.

At the same time, in these early phases implementation varied among different states. While subjected to central government's general policy guidelines, states have considerable power over PDS implementation, including the ability to set food subsidy rates and distribution parameters in terms of benefits and beneficiaries. As a result, despite the universality of PDS at the central level, some states elaborated pro-poor schemes designed specifically for vulnerable groups. For example, in the Green Card Scheme implemented in the 1980s in Karnataka, 40 percent of the population was entitled to a "Green Card" which gave them the right to higher subsidies from the PDS (Mooij 1998:87-8). In spite of this state-level targeting, at the national level, the system remained universal and grounded on homogeneous prices.

\section{PDS: Targeting and Its Consequences}

In the 1990s the PDS was subjected to profound changes. The universality of the system had exposed it to two major critiques: an urban bias was found in public distribution, which largely excluded rural communities from the system (Howes and Jha 1992; Dantwala 2006). ${ }^{5}$ Systemic leakage to non-poor recipients also caused concerns of public expenditure, as providing a subsidy to all citizens incurred expenses that India, facing a severe fiscal crisis, could not possibly sustain (Radhakrishna 1996; Dutta and Ramaswami 2001; Umali-Deininger and Deininger 2001; Ramaswami and Balakrishnan 2002).

Reforms to the scheme, culminating in the adoption of a new targeted system in 1997, were an integral part of the neoliberal reforms that India embarked upon in the early 1990s. At that time state interventionism, which predominated as a government 
philosophy in the first decades after Independence (Corbridge and Harriss 2000), was contested due to the systemic economic and distributional inefficiencies attributed to it (Radhakrishna and Subbarao 1997; Umali-Deininger and Deininger 2001). What was put forward in its place was a form of neoliberal thought that framed the solution as two concomitant actions: consistent reductions in public expenditure on social protection on the one hand, and the introduction of open competition in the country's economy on the other (Corbridge and Harriss 2000). These interventions ascribed to the philosophy of New Public Management, a style of government that fosters effectiveness by minimizing the role of the state and adopting incentives proper of the private sector.

17 As an integral part of its project of economic liberalization, in 1991 India embarked upon a Structural Adjustment Programme, aimed at ending the ongoing fiscal crisis and relaunching the economy through neoliberal reforms. At the core of the project was the view of markets as the means to solve the inefficiencies that the nation experienced: the project saw the role of the state as a protector of property rights and ultimately, a mere guarantor of the proper functioning of markets (Corbridge and Harriss 2000). The state was therefore induced to refrain from market interventions, to limit the risk of systemic inefficiencies (Harvey 2005). The overarching idea of a neoliberal solution, which saw market openness as a key driver and state intervention as a hurdle, characterized the India of the early 1990s, resulting in the restructuring of systems of social assistance in ways that sought to maximize economic manageability.

18 The need for reduction in the national public expenditure, a direct prescription of the Structural Adjustment Programme, had visible consequences on the management of the PDS. Severe inefficiencies were substantiated in the point, made by World Bank economists, that the system enabled "meagre transfer at exorbitant cost" (Radhakrishna and Subbarao 1997:7) due to its universal nature, while fiscal expenditures were reported to yield long-term distortions on private markets ultimately hurting the poor (Ramaswami and Balakrishnan 2002). Such concerns became the root of the new targeted PDS, which converted universal provision into reservation of subsidy to below-poverty-line (BPL) households.

19 This new PDS, introduced in the nation in June 1997, represented a changed rationale behind which were two fundamental structural changes:

20 - First, the program shifted away from universal provision to channels of subsidy distribution restricted to the BPL category while providing states some leeway to maintain a minimum subsidy for the APL. A higher subsidy was introduced for the poorest of the poor, classified under the Antiyodaya Anna Yojana (AAY) scheme. Qualification for both BPL and AAY categories was now determined in accordance with periodically reviewed income-based poverty lines.

21 - Second, the universal PDS had allocated goods to states based on theoretical requirement. In the targeted system, commodities began to be allocated on the basis of relative state poverty: the central government prepares individual estimates of poverty incidence on each state, and on the basis of these estimates supplies of goods are allocated proportionally (Tritah 2003).

22 To combat a structural drawback of the universal system, subsidies on essential goods were reserved for the needy, in order to eliminate dispersal to the economically secure. As a result of the targeted PDS, the central government's fiscal subsidy expenditure was effectively reduced (Umali-Deininger and Deininger 2001:328). Another effect of this 
move was that APL citizens, left with little or no subsidy on PDS commodities, largely opted out of the PDS and returned to purchasing essential goods on the free market.

In the debate on social protection systems, one school of thought supports targeting as it not only provides the means of reducing fiscal expenditure, but also an ability to cope with the needs of a large poor and undernourished population. Another stream argues the targeted PDS does not successfully avoid exclusion errors leading to serious disruptions in food security (e.g. Swaminathan 2008; Khera 2011a; Sen and Himanshu 2011; Drèze and Khera 2015).

Among the nation's 29 states, the experience of Kerala is a clear example of the transition issues involved in the switch to a targeted PDS. Before 1997, Kerala was recognized as operating the best state-level PDS in India (Swaminathan 2002). Under the initial universal system PDS distribution catered to 97 percent of the state's population (George 1979:23) and the impact on beneficiaries' nutritional status was high and significant (Kumar 1979). However after the implementation of targeting in 1997, the state-level system endured three orders of entitlement access problems:

- As a result of centralized poverty assessments, allocation of foodgrains to the state was reduced to an amount lower than 10 percent of the pre-targeting supply (Swaminathan 2002:51). Poverty incidence in the state was estimated at just 25 percent, significantly reducing allocation of goods to beneficiaries. The state government reestimated poverty from 25 percent to 42 percent of the population, but a drop in available supplies still hindered entitlements.

26 - After 1997, households recognized as APL opted out the system in vast numbers, as a result of the sharp reduction in subsidy reserved for them. This is reflected in data on the overall offtake of cereals: as per Khera's (2011b:107) estimates, statewide purchases from the PDS dropped from 4.64 tons in 1997 to 1.71 tons in 2001. Kerala is one of the states where a subsidy to the APL, while minimal, still exists at the present time, but given its comparatively limited quantities many former beneficiaries were de facto excluded from it.

27 - Following the sudden shrink of the customer base, many ration shops became unviable and closed down (Krishnakumar 2000). The drastic reduction in foodgrain supplies, and the factual exclusion of the APL from purchases, created a situation in which ration shops were made unviable, with consequences in terms of debt that resulted in a wave of suicides among ration dealers (Suchitra 2004) and many ration shops closing down.

28 As a consequence, direct or indirect, of those conditions listed above, PDS actors largely engaged in illegal sales on the private market, where standard prices are higher generating substantial profits for those who go undetected. Leakage of PDS goods on the private market, a phenomenon termed "rice mafia" by the Justice Wadhwa Committee on PDS (2010), undermines the viability of the PDS and, as the body of scholars mentioned above points out, ultimately prevents exactly the food security that the system is aimed at guaranteeing for all residents.

29 Systematic leakage constitutes a serious issue in the program and the principal disruption to its normal functioning (Saini, et al 2017). While different states have taken different measures for accountability enforcement over time, targeting has reduced the customer base of ration shops, which are left in dire need of new resources for business continuation. Khera's (2011a:1058) note that "corruption has become a 
requirement of economic survival for the PDS dealers" constitutes a first-order problem in the PDS, undermining its ability to effectively serve its beneficiaries.

\section{PDS Computerization: From State-Level Systems to Aadhaar} central government, which is in charge of policy formulation, makes decisions on procurement and allocation based on state population and relative shares of BPL households (Tritah 2003:5). State governments implement and manage the PDS, making decisions on crucial factors such as offtake, the location of ration shops, and the list of goods provided through the program (Tritah 2003:6). While the issue price is determined centrally, state governments are allowed to modify it as a result of the additional costs of stock and delivery (Tritah 2003:6), and are in charge of operational decisions on program management to facilitate delivery and combat diversion at the sub-national level (Khera 2011b). as a measure configured to fix the multiple crises induced by targeting. In Kerala the PDS was digitized across three different phases: the first consisted in the creation of a digital database, stored at the level of taluks (sub-district administrative units), in which details of all users of the PDS were registered. The second coincided with the implementation of a software package automatizing the key functions of PDS in Taluk Supply Offices (TSOs), the offices in charge of the local administration of the program. The third phase, started with a pilot scheme in 2012, consists of integrating the distribution system with Aadhaar-India's biometric population database. This scheme allowed PDS users to obtain their entitlements from ration shops using a secure identification system.

The experience of Kerala is paradigmatic of that of other states such as Chhattisgarh, Gujarat and Karnataka which embarked on early forms of computerization of their PDS'. In Chhattisgarh, priority was given to computerization of the back-end phases of the PDS and a tracking system was built to control diversion in the early stages of the supply chain (Rajan, Chopra, Somashekar and Laux 2016). In Gujarat and Karnataka, biometric identification was implemented in ration shops even prior to Aadhaar seeding, to guarantee the authenticity of users' entitlement and combat ration dealers' malpractice. The Aadhaar system, launched in 2009, provided a common national matrix to underpin efforts of biometric identification.

In January 2009 the Government of India set up the Unique Identification Authority of India (UIDAI) to collect the biometric data of all residents, store them in a central database, and give each enrollee a unique 12-digit number. In June 2009, Nandan Nilekani (the co-founder of Infosys, a large technology services enterprise) was appointed as the first head of UIDAI, which was established as an office of the Planning Commission of the Central Government. Starting from 2010, Aadhaar enrolment centers were set up across the nation and state governments led proactive campaigns to increase their residents' adherence to the scheme. The National Democratic Alliance (NDA) government has supported continuation of the scheme, which originated under the previous United Progressive Alliance (UPA) government, and especially fostered its inscription in the social protection system designed to serve the poor (Bhatia and 
Bhabha 2017). This makes Aadhaar an integral part of India's social policy, and the government's strategy openly incorporates it in the fight to work against the leakage that affects the PDS (Government of India 2015). In August 201989.2 percent of the population had an Aadhaar number assigned, and high enrolment rates were achieved even in India's poorest states. ${ }^{6}$ With more than 1.2 billion numbers issued to residents, Aadhaar is now the biggest biometric database in the world, explicitly linked to the provision of public services and social welfare. ${ }^{7}$

Effective incorporation of Aadhaar in the PDS started in 2011-2012, with pilot projects undertaken at the local level in different states (Saini et al. 2017). These projects introduced Aadhaar recognition in the ration shop space that constitutes the last mile of the supply chain. In the East Godavari district of Andhra Pradesh, one of the first in the country to pilot the scheme, PDS beneficiaries were requested to register with Aadhaar and their identification number was linked with the ration card database which reported on their poverty status. Ration shops were endowed with biometric point-of-sale machines set to recognize beneficiaries through their fingerprint, hence delivering the exact monthly allotment to which each user was entitled.

State-level instances of Aadhaar-based PDS were justified with the establishment of a two-fold accountability mechanism aimed at guaranteeing the entitlement of beneficiaries and simultaneously, preventing ration dealers from engaging in illegal sales. These schemes were initially confined to the stage of pilot projects, as a Supreme Court order in September 2013 prohibited making Aadhaar a mandatory requirement for access to anti-poverty programs. Public debate centered on the extent to which enrolment was effectively non-coercive, given the increasing entrenchment of Aadhaar authentication in the large majority of public services. In August 2015, a new Supreme Court order made it possible for states to use Aadhaar in their PDS schemes.

In March 2016, the Targeted Delivery of Financial and Other Subsidies, Benefits and Services Act was passed in Parliament, providing legal backing to the incorporation of Aadhaar in state-level PDS implementations. Criticism emerged around the governing coalition's choice to pass the act as a Money Bill, a legislative act which is directly enforced once passed in the Lower House without sanctioning by the Upper House of Parliament. Finding its origins in the National Identification Authority of India Bill passed in 2010, the Aadhaar Bill enabled states to include Aadhaar identification in their social protection schemes, and thus state-level PDS implementations to become officially Aadhaar-based. As it afforded a formal shift to biometrics in anti-poverty core programs, the Bill is viewed as the final act of incorporating Aadhaar in the social protection system.

Interwoven with the debate on social protection, there are growing concerns about Aadhaar's affordances in developing a surveillance state, in which private parties would access UIDAI data without reliable controls (Rao and Nair 2019:477). Addressing such preoccupations, the Supreme Court emitted a final verdict in September 2018, declaring Aadhaar's constitutionality in the light of its role in strengthening social welfare. The verdict directly connects Aadhaar to its affordances in public welfare delivery, and for the same reason it limits its use by private parties with commercial purposes (Rao and Nair 2019:477). In continuity with the Aadhaar bill, the verdict frames digital identification into the functional role of enabler of public services, hence backing the continued entrenchment on Aadhaar in national social protection schemes. 


\section{The Aadhaar-Based PDS: Effects on Entitlements}

Based on the experiences of Kerala and Karnataka, two states that adopted an Aadhaarbased PDS after an earlier history of digitization, the transition to biometric recognition has yielded a set of seemingly positive short-term effects, three of which have emerged from my research: reduced ration dealer incentive to corruption, strengthened leakage controls, and the affordance (still not actualized) of enabling recipients to opt out of the ration shop they are registered with, upon suspicion of diversion by the ration dealer. The three types of effects are illustrated below.

First, an Aadhaar-based PDS reduces the incentive for ration dealers to sell goods on the market instead of targeting genuinely entitled recipients. The mechanism underlying this is grounded on how, enabling secure identification of beneficiaries, a biometric system tackles the problem of fake transaction records, which-as data from both states reveal-were used by ration dealers to hide the conduct of illegal transactions on private markets (Masiero 2015; Prakash and Masiero 2015). Fake transactions, normally justified through bogus ration card numbers, allowed ration dealers to claim having sold to entitled recipients at PDS prices, while selling on private markets and generating illicit profits. The Aadhaar infrastructure verifies identification through biometrics: the invention of non-existing customers thus becomes difficult to enact, diminishing the opportunity for corruption of the system by ration dealers.

Second, controls on leakage are strengthened as the Aadhaar-verified identity of customers is used to monitor the offtake of goods from ration shops. Beyond checking the identity of buyers, point-of-sale machines register the amount of commodities sold at every transaction: all sales of PDS goods are thus recorded in a dedicated database, further reducing ration dealers' ability to invent sales that have not occurred in practice. In addition, the system allows verification that sold quantities match those received by ration shops after monthly allocation, making it difficult for ration dealers to claim "running out" of goods and then divert them to the market. This mechanism complements the control on bogus ration cards, especially given that ration dealers cannot register for fresh ration stocks until the quantity for a given month has been completely disbursed.

A third mechanism, acting on the demand side, proposes to delink ration shops from the households registered with each of them. Every household was originally linked to one ration shop, and hence able to buy PDS goods only from it. As a result, even if customers become aware of ration dealer misbehavior (most frequently enacted by underselling or claiming "running out" of goods), they have no option to purchase from a different dealer. Aadhaar-based point-of-sale machines, however, afford the possibility to recognize all residents registered with the system, hence enabling a "portable" PDS in which purchases could be made from any ration shop. While this " delinking" has not yet occurred, the technology is designed and implemented in such a way to enable it, and a system operating in this way would enable recipients to opt out of ration shops indulging in illicit behavior.

Proponents of the system argue that the combination of reduction in corruption incentives, controls on diversion, and delinking users from ration shops makes an Aadhaar-based PDS more effective and accountable, reducing the inclusion errors that affect the system as a whole (Gulati and Saini 2015; Saini et al. 2017). Inclusion errors occur when a targeted system erroneously includes non-entitled beneficiaries, such as 
agents in the private markets or owners of bogus ration cards. Technology-based interventions on state-level PDS have already shown their effectiveness especially in Chhattisgarh, where an automatized system (COREPDS) has been instrumental to program improvement, offering an alternative to Aadhaar that creates new forms of back-end monitoring and reduces estimated diversion (Rajan et al. 2016; Khera 2018). In Kerala, where post-targeting problems had been significant, computerization has improved the ability to allocate goods at the ration shop level and monitor offtake from the program (Masiero 2015).

As I have argued elsewhere (Masiero 2017) however, experiences of Aadhaar-based PDS are just a component of the grand design of change behind the scheme. Understanding such design requires attention to a composite infrastructure, first announced in the Economic Survey 2014-2015, in which Aadhaar is combined with two more technologies: a financial inclusion program (the Pradhan Mantri Jan Dhan Yojana, commonly referred to simply as Jan Dhan Yojana), and mobile phones, whose ownership by vulnerable segments of the population has increased over the last decades. A flagship scheme of the NDA government, Jan Dhan Yojana aims at providing lower-income households with a bank account, which will constitute the backbone core infrastructure for the direct transfer of benefits to those entitled. The program was launched in 2015 and led to the opening of millions of zero-balance bank accounts for BPL households, in an effort towards financial inclusion of marginalized communities (Kaur and Singh 2015).

The combination of Jan Dhan Yojana, Aadhaar and mobile payments, acronymized as “JAM trinity" in the current governments' narrative, is planned with the explicit purpose of rebuilding the nation's anti-poverty system by converting existing subsidies into a lump-sum transfer to the BPL (Government of India 2015:64). The concept of financialization, used in development studies to refer to the increased use of financial instruments in development policy (Young 2010), powerfully captures the rationale behind the JAM ecosystem. Behind it is the idea that in-kind subsidies, while widely deployed as a means to anti-poverty policy, do not constitute an ideal solution for the delivery of social protection schemes, as they suffer from multiple issues (they are identified in the Economic Survey 2014-2015 as being regressive, distorting the market in ways that harm the poor, and being prone to leakage and diversion). As a result, development policies based on novel financial instruments are encouraged whether developed from scratch or on top of previously constructed development schemes infrastructures.

Importantly in this context, the implementation of the JAM trinity has precise implications for the future of the PDS and India's social protection at large. At present, various states are engaging in the move to Aadhaar-based systems, where biometric infrastructures are built into the program as it was. As specified in the Economic Survey 2014-2015, the JAM trinity serves instead to prepare a move to a new scheme of direct transfers, transforming food rations into transfers of cash direct to beneficiaries' bank accounts (Government of India 2015:64-65). As reported by the Survey, the new scheme serves to eliminate PDS leakages and the distortions induced by subsidies.

The shift from PDS to cash transfers has already been piloted in Pondicherry, Chandigarh, Dadra and Nagar Haveli, ${ }^{8}$ and is at the center of debate in Indian social policy (e.g. Svedberg 2012; Khera 2014; Chanchani 2017). Advocates of the policy shift point to the structural ineffectiveness of the PDS, arguing that leakages and distortions 
brought in by state subsidies need elimination at the roots, but a growing set of narratives has emerged in opposition to this, raising concerns with Aadhaar-based PDS and the JAM trinity alike. In my research on the PDS through the years, three core problems have emerged: these revolve around technical fragilities, the persistence of exclusion errors, and the shift in food governance structures determined by the passage from the PDS to a market-led system.

Technical fragilities emerge from project complexities, specifically implementation of diverse infrastructures to automatize monitoring of sales and offtake. The problem of technical fragility emerged with particular visibility early in the Aadhaar-based PDS adoption process and affected multiple states in the nation, for instance in Rajasthan there were violent demonstrations and cases of vandalism of ration shop POS machines, motivated by people's frustration with the malfunctions of the new system. ${ }^{9}$ The problem induced by technical fragilities is powerfully summarized by the economist Jean Drèze:

\footnotetext{
This system requires multiple fragile technologies to work at the same time: the PoS machine, the biometrics, the internet connection, remote servers and often other elements such as the local mobile network. Further, it requires at least some household members to have an Aadhaar number, correctly seeded in the PDS database (cited in Shagun and Aditi 2016).
}

Infrastructural complexity leads to system malfunctions registered in diverse states and regions and casting doubt on claims of Aadhaar-based PDS effectiveness (Drèze and Khera 2017). Malfunctions run the risk of exacerbating exclusion errors. This is identified as the main problem brought by the PDS transformation to a targeted system (Swaminathan 2008; Khera 2011a). The term "exclusion errors" refers to problems that lead genuinely needful households to be excluded from targeted programs due to erroneous categorization of their status or ineffective delivery mechanisms (Tritah 2003). If users are not recognized from the front-end interface of the biometric PDS, the risk is that of exclusion from access to food rations, an outcome that has already been noted in biometrically enabled systems across the nation (Masiero and Prakash 2015; Drèze and Khera 2017).

Some commentators classify such problems as transitory rather than structural, since they pertain to technological implementation and not to the structural properties (i.e. the intrinsic technological features) of the new system. If technological improvements were sufficient, few issues would remain in the program, such as the limited profit margins of ration dealers-resulting in continuation of incentives to corruption. Supporters argue issues of this type are a legacy of the shift to a targeted system, and may persist in spite of the checks introduced by the new technology. Proponents of the new direct transfer benefit policy argue that a shift to a cash transfer system would eliminate the roots of the problem, since ration shops could be eliminated (Saini et al. 2017).

What remains problematic, however, is the change in food governance that this entails, which has been problematized by bureaucrats and PDS users alike. As in the early days of its implementation, the PDS is managed by state governments and run by bureaucracies that, despite the multiple issues illustrated above, are familiar to recipients of the program. A move to cash transfers would radically change existing governance structures, shifting control from state bureaucracies to markets in which recipients would purchase their goods. While the move is justified by the purpose of 
elimination of leakages and distortion, commentators observe that the transition entails exasperation of the risk of exclusion errors, which might endanger the greater effectiveness brought about by reforms (Drèze and Khera 2017; Chanchani 2017).

These observations are reflected in my latest study of the Aadhaar-based PDS in Karnataka (Masiero and Das 2019). To our question of whether they would welcome a transition from the current in-kind subsidies to cash transfers, recipients provided quasi-unanimous negative responses, motivated by three main reasons. Firstly, PDS beneficiaries place high value on the perceived security of material rations, which is not seen as guaranteed in the case of replacement with a monthly sum of cash. Secondly, the trusted routine of monthly visits to the ration shops is portrayed by respondents as a highly valued practice, relied upon as means to ensure a safe ration of basic-need goods for the household..$^{10}$ Third, a minority of respondents have pointed out issues of unequal access to finances within the house, displaying the concern that male household members may divert cash benefits away from their purpose. While all these reasons to prefer food to cash were put forward, recipients displayed limited awareness of the purposeful link between the Aadhaar-based PDS and the objective to shift to a system of direct benefits constructed through the JAM trinity.

To sum up, the history of the Aadhaar-based PDS recounted here reveals the transformative power that biometric technologies, reconstructing the last mile of the scheme's supply chain, yield on anti-poverty programs. If not inscribed in its policy context, such transformation may be seen as an incremental fix, consisting in the provision of biometric security to combat the issue of market diversion. But the policy intention behind it, that of transitioning to a cash transfer system that eliminates the distortions and opportunities for leakage brought about by subsidy, marks a radical change in the program's architecture, whose ability of enacting effective pro-poor structures remains to be assessed. Viewed in this light, the biometric reconstruction of the PDS constitutes a political transformation that will have substantial consequences on the entitlements of program recipients.

\section{Discussion}

This section positions the argument on biometrically-induced transformation of the PDS into two streams of literature, one of which pertains to coded citizenship and especially to the debate on datafication of anti-poverty programs within it. The second stream is centered on Indian social policy and on the need to find ways to combat the exclusion errors that persist in spite of the biometric transformation of the scheme (Drèze and Khera 2017; Khera 2019).

\section{Coded Citizenship: Datafication of Anti-Poverty Programs}

The notion of coded citizenship refers to the transformation of populations into data, as a result of which the citizen becomes machine-readable as an ensemble of data (Srinivasan and Johri 2014). This concept is increasingly interpreted as the datafication of populations (Rao and Nair 2019), and seen in historical continuity with the technologies of rule used to administer subjects in colonial times. The lens of citizenstate relations is widely used to study India's Aadhaar, both as a top-down means of control and surveillance and as an infrastructure through which India's residents 
access the state (cf. Bhatia and Bhabha 2017; Chaudhuri and König 2018; Hosein and Whitley 2019; Singh 2019; Rao 2019; Nair 2019). Viewing the incorporation of Aadhaar as the latest phase of a longer process of PDS computerization, my research presents some reflections for this debate.

First, as a datafier of the population of Indian residents, Aadhaar converts individual recipients of programs such as the PDS into machine-readable data. By its own nature, this process allows the automatization of two functions of the scheme: the recognition of entitled vs. non-entitled users and the assignation of entitlements according to data (Masiero and Das 2019). While the same functions were present in the manual PDS, Aadhaar makes them data-mediated in ways that change not only the architecture of the program, but also recipients' ways to access their entitlements. This leads to the point that datafication acquires a particular meaning when related to anti-poverty schemes, which opens a new area of enquiry-here termed the datafication of antipoverty programs-centered specifically on the effects of data on program architectures and recipients' entitlements.

Secondly, the work presented here subscribes to the stream which considers Aadhaar in relation to how residents see the state (Chaudhuri and König 2018; Rao 2019). In particular, my data suggest that citizens "form an image" of the state that is directly mediated by technology, which hence should be studied through the direct encounters of PDS recipients with it (Masiero 2017). The volume of Aadhaar ethnographies edited by Rao and Nair (2019) focuses specifically on such encounters, offering multiple perspectives on how these are embedded in the lives of residents. This suggests that, in studying datafied anti-poverty programs, it is important to combine studies of infrastructural power (such as, for example, the designers' perspective offered by Singh 2019) with the study of local-level encounters, through the technology-mediated spaces in which the citizen encounters the state.

In addition, the concept of data justice-recent but prominent in the literature of datafication-proves useful in exploring cases of datafied schemes such as the Aadhaarmediated PDS. The object of a recent debate (Dencik et al. 2019), the notion of data justice indicates "fairness in the way people are made visible, represented and treated as a result of their production of digital data" (Taylor 2017:1). Literature on data justice investigates representations of people in a datafied world, addressing issues of fairness and security which have global relevance (Dencik et al. 2019); issues which are still particularly relevant in the Global South in the light of datafied anti-poverty schemes and of the structural drivers that influence the condition of the world's poor (Heeks and Renken 2018).

Quoting Masiero and Das (2019), the data presented in my research of the Aadhaarbased PDS reveal three limitations to the enactment of data justice in datafied antipoverty programs. A first limitation, of a legal nature, shows how the Aadhaar-based PDS-while remaining within the boundaries of constitutionality-confines access to enrolled residents, effectively subordinating the right-to-food to registration in a biometric identification scheme. This echoes the point by Ramanathan (2014) that the poor have no choice when it comes to enrolment as in the new scheme registration is an essential requirement for receiving any form of social protection. While advocates maintain that welfare objectives justify the conditionality of social protection to registration, fieldwork shows a lacuna for those recipients for whom lack of biometric recognition is a cause for denial of rations. 
58 Two more limitations to data justice emerge from the research, whose natures are respectively design-related and informational (Masiero and Das 2019). A design-related limit relates to the finding that the Aadhaar-based PDS focuses on inclusion errors, while biometric recognition technology leaves exclusion errors unattended. In terms of the informational aspect, the limitation lies in the incompleteness of information received by PDS beneficiaries on the transformative goal of Aadhaar. In contrast, this goal which is mirrored by the very structure and enactment of the JAM trinity technologies is clear in the Economic Survey 2014-2015, the report with which the JAM trinity was launched:

(...) the JAM Number Trinity can be seamlessly linked, and all subsidies rolled into one or a few monthly transfers, real progress in terms of direct income support to the poor may finally be possible. The heady prospect for the Indian economy is that, with strong investments in state capacity, that Nirvana today seems within reach. It will be a Nirvana for two reasons: the poor will be protected and provided for; and many prices in India will be liberated to perform their role of efficiently allocating resources in the economy and boosting long run growth. (Government of India 2015:65).

When talking to PDS users however, this broader goal has very seldom been brought up by interviewees, while Aadhaar is mostly considered in the context of encounters with it-in the ration shops where the PDS is accessed-and therefore, as an instrument for improvement of the PDS rather than for enactment of broader change. Conversely, the underlying JAM trinity goal of moving from subsidies to a cash transfers system does not appear in conversations with beneficiaries, whose attitudes towards such a move, as it emerges from interviews, are generally suspicious. These limits to data justice, seen in a case of datafication of a large social protection system, require further research in the domain of datafication of anti-poverty programs.

Finally, a limitation lies in the lens this research has adopted. Citizen-state relations surely offer a lens through which to read the Aadhaar case, and it does make sense to use such a lens in a case in which Aadhaar mediates a state-led program such as the PDS. Yet other researchers, for example Solanki (2019), warn about the limitations of the citizen-state lens, which does not contemplate many aspects-such as intrabureaucratic relations-that should be discussed in a program which regulates people's lives not only as citizens but also as workers and consumers. While limited by the Supreme Court verdict of 2018, the ubiquity of Aadhaar invites us to consider perspectives that look beyond the sheer domain of the state-citizen relation.

\section{Social Policy: Combating the Exclusion Error}

In the aftermath of the Aadhaar Bill and of the Supreme Court verdict on the constitutionality of the program, the Aadhaar-based transformation of social protection schemes has been at the center of the Indian social policy debate. As shown in this paper, over the last decade the PDS has been profoundly transformed by digital and biometric technologies. Technological transformation, coupled with the constant need for secure social protection for the Indian poor, calls for reflection on how statelevel computerized PDS can combat the exclusion errors that persist in it. This is in line with the NFSA goal to provide PDS foodgrains to around two thirds of the Indian population, and three core considerations emerge from my research. 
61 First, as observed over time in both fieldwork states, it is important to design technologies that involve the early stages of the PDS supply chain. In particular, digital systems of allocation and monitoring play a major role in tackling issues of diversion that occur before goods reach the ration shops. By doing so they tackle the crucial node of diversion, since substantial portions of leakage occur during the important, but under monitored stages of transportation and storage (Khera 2011b). While political appeal of front-end technologies is comparatively greater, back-end systems are of fundamental importance in restructuring the PDS, and they play a major role in extending the actual coverage of the program.

Second, technology has a role in combating the root causes of diversion, including the pressures for ration dealers to find secure sources of income after the crisis induced by targeting. In the aftermath of the shift to a targeted system, some states have resorted to credit concessions to ration dealers (Swaminathan 2008), while others have allowed sales of non-PDS commodities in ration shops to ensure business continuity. Others, however, have used technology to ensure that all ration shops receive their theoretical requirement and are enabled to conduct business. If technology can be used to strengthen the PDS in its current form, this suggests that there are alternatives to dismantling the system in favor of direct transfers, and the use of technology for strengthening the existing PDS should be compared and contrasted with that possibility (Masiero 2015; Khera 2017).

63 A recent study by Allu, Deo and Devalkar (2019) offers a thorough review of the alternatives to Aadhaar-based biometrics in the PDS. The authors propose a taxonomy of methods along three dimensions: "mode of authentication, biometric or nonbiometric, source of authentication, central database connected through internet or locally stored data in the point of sale device (ePos), frequency of authentication, at every transaction or once for a predefined number of transactions" (Allu, Deo and Devalkar 2019:2). Based on the experience of digitized PDS in eight different states, the authors observe how most benefits in performance are associated with the use of biometrics during registration, while biometric authentication at ration shops is not systematically associated to more effective systems. In the light of these results, it is important that states evaluate different alternatives before scaling up Aadhaar-based identification to all their ration shops. In another study, Khera (2018) observes that other options than Aadhaar authentication at the ration shop are available to monitor PDS leakage. She reviews two different options: in Chhattisgarh's COREPDS experiment, which began in 2012, ration shop transactions were enabled by smart cards with an embedded memory chip, hence every transaction was recorded on the chip and uploaded online. In Tamil Nadu, QRcoded smart cards maintain a digital trail of all transactions, using a smart card reader in the ration shop-in lieu of the Aadhaar-enabled point of sale machine. Comparing these two alternatives to Aadhaar-based biometric authentication, Khera highlights the significant advantages of such alternatives, observing that smart cards-be them QRcoded, or with embedded memory chips-offer substantial advantages, also enabling immobile persons (such as the elderly) to rely on other persons to fetch PDS commodities.

65 Finally, as a consequence of the need to minimize exclusion errors, the state-level experiences reviewed here highlight the importance of backup mechanisms for user recognition. There is a particularly pressing need for measures of this type, since 
disempowerment caused by user exclusion compensates the theoretical benefits that computerization may bring. In an earlier study of Karnataka (Masiero and Prakash 2015) it had emerged that, in a limited number of ration shops, ration dealers resorted to paper-based records of transactions to bypass the point-of-sale machine in case of malfunctioning. This was, however, not the case when we returned to the field in 2018. More encompassing mechanisms of redressal are needed, especially after the Aadhaar Bill enabled state-level systems to become entirely Aadhaar-based. While enrolment is now very high among Indian residents, failure of Aadhaar-based authentication still occurs, and to effectively ensure the right to food to it needs to be integrated with alternative forms of authentication or state-level databases.

\section{Conclusion}

From the research on computerization of the PDS presented here, two final considerations can be drawn on the relation between technology developments and social welfare systems. Firstly, the hegemonic narrative on technology-induced leaps in the effectiveness of social protection systems is problematized by the considerations offered here. What we witness in the biometric PDS is a history of winners and losers, which juxtaposes reform with problems of exclusion, technological malfunctioning and undesired shifts in the making of program governance. While digital tools may well be entrenched in program improvement, technical errors related to access entitlement and data injustices may become equally pervasive, and prevent the system from achieving the goals of effective coverage that were established for it.

Secondly, the JAM trinity-enabled move from PDS to cash transfers needs careful evaluation to avoid exacerbation of the exclusion errors that already affect the system. While such transition is still under discussion, its risks and benefits should be balanced against those of technologies that preserve the existing PDS instead of dismantling it. State-level stories of PDS reform lead to the argument that an alternative to cash transfers is possible, and would avoid the major costs and disruption that transition to the new system would entail, even if implemented and phased in gradually across the nation. Hence, alternative options need to be evaluated, in the light of the ability of each proposed solution to provide secure entitlements to PDS recipients.

\section{BIBLIOGRAPHY}

Ahluwalia, Deepak. 1993. "Public Distribution of Food in India: Coverage, Targeting and Leakages." Food Policy 18(1):33-54.

Allu, Rakesh, Sarang Deo, and Sripad K. Devalkar. 2019. "Alternatives to Aadhaar Based Biometrics in the Public Distribution System." Economic and Political Weekly 54(12):30-7.

Bhatia, Amiya, and Jacqueline Bhabha. 2017. "India's Aadhaar Scheme and the Promise of Inclusive Social Protection.” Oxford Development Studies 45(1):64-79. 
Bhatia, B. M. 1991. Famines in India: A study in some aspects of the economic history of India with special reference to the food problem, 1860-1900. New Delhi: Konark.

Chanchani, Devanshi. 2017. "Would the People of Chhattisgarh Prefer Cash Transfers instead of Foodgrain?" Economic and Political Weekly 39(32):7-11.

Chaudhuri, Bidisha, and Lion König. 2018. "The Aadhaar Scheme: A Cornerstone of a New Citizenship Regime in India?" Contemporary South Asia 26(2):127-42.

Corbridge, Stuart, and John Harriss. 2000. Reinventing India: Liberalisation, Hindu Nationalism and Popular Democracy. London: Polity Press.

Dantwala, M. L. 2006. “Agricultural Policy: Prices and Public Distribution System.” Pp. 153-72 in Indian Agriculture in the New Millennium: Changing Perceptions and Development Policy, edited by N.A. Mujumdar and U. Kapila. New Delhi: Academic Foundation.

Deaton, Angus. 2003. “Adjusted Indian Poverty Estimates for 1999-2000." Economic and Political Weekly 38(4):322-6.

Dencik, Lina, Arne Hintz, Joanna Redden, and Emiliano Treré. 2019. "Exploring Data Justice: Conceptions, Applications and Directions." Information, Communication and Society 22(7):873-81.

Dev, S.M., and M.H. Suryanarayana. 1991. "Is PDS Urban Biased and Pro-Rich? An Evaluation." Economic and Political Weekly 26(41):2357-66.

Drèze, Jean, and Reetika Khera. 2015. "Understanding Leakages in the Public Distribution System." Economic and Political Weekly 50(7):39-42.

Drèze, Jean, and Reetika Khera. 2017. "Recent Social Security Initiatives in India.” World Development 98:555-72.

Dutta, Bhaskar, and Barat Ramaswami. 2001. "Targeting and Efficiency in the Public Distribution System: Case of Andhra Pradesh and Maharashtra." Economic and Political Weekly 36(18):1524-32.

George, Poykayil Simon. 1979. Public Distribution of Foodgrains in Kerala: Income Distribution Implications and Effectiveness. Washington, DC: International Food Policy Research Institute (IFPRI).

Government of India. 2015. "Wiping Every Tear from Every Eye: The JAM Trinity Number Solution.” Economic Survey 2014-2015. Retrieved November 18, 2019 (https:// www.indiabudget.gov.in/budget2015-2016/es2014-15/echapvol1-03.pdf).

Gulati, Ashok, and Shweta Saini. 2015. "Leakages from Public Distribution System (PDS) and the Way Forward.” ICRIER Working Paper No. 294, ICRIER-ZEF Project.

Kaur, H., and K.N. Singh. 2015. "Pradhan Mantri Jan Dhan Yojana: A Leap towards Financial Inclusion in India." International Journal of Emerging Research in Management and Technology 4(1):259.

Khera, Reetika. 2011a. “India's Public Distribution System: Utilisation and Impact.” Journal of Development Studies 47(7):1038-60.

Khera, Reetika. 2011b. “Trends in Diversion of Grain from the Public Distribution System.” Economic and Political Weekly 46(21):106-14.

Khera, Reetika. 2014. "Cash vs. In-kind Transfers: Indian Data Meets Theory." Food Policy 46:11628.

Khera, Reetika. 2017. "Impact of Aadhaar in Welfare Programmes." Retrieved on November 18, 2019 (https://papers.ssrn.com/sol3/papers.cfm?abstract_id=3045235). 
Khera, Reetika. 2018. "Smarter than Aadhaar: Govt's Insistence on Disruptive Option is Bewildering." Business Standard, March 14, 2018. Retrieved on April 23, 2020 (https:// www.business-standard.com/article/opinion/how-successfully-last-mile-authentication-hasrecorded-pds-118031301260_1.html).

Khera, Reetika. 2019. Dissent on Aadhaar: Big Data Meets Big Brother. Hyderabad: Orient BlackSwan.

Krishnakumar. R. 2000. “Public Distribution System: A System in Peril.” Frontline 17(19):16-29.

Kumar, Shubh K. 1979. Impact of Subsidized Rice on Food Consumption and Nutrition in Kerala. Washington, DC: International Food Policy Research Institute (IFPRI).

Harvey, David. 2005. Spaces of Neoliberalization: Towards a Theory of Uneven Geographical Development. London: Franz Steiner Verlag.

Heeks, Richard, and Jaco Renken. 2018. “Data Justice for Development: What Would It Mean?" Information Development 34(1):90-102.

Himanshu. 2007. "Recent Trends in Poverty and Inequality: Some Preliminary Results." Economic and Political Weekly 42(6):497-508.

Hosein, Gus, and Edgar A. Whitley. 2019. “Identity and Development: Questioning Aadhaar's Digital Credentials.” Pp. 219-38 in Dissent on Aadhaar: Big Data Meets Big Brother, edited by R. Khera. Hyderabad: Orient Black Swan.

Howes, Stephen, and Shikha Jha. 1992. "Urban Bias in Indian Public Distribution System." Economic and Political Weekly 27(19):1022-30.

Masiero, Silvia. 2014. "Imagining the State through Digital Technologies: A Case of State-level Computerization in the Indian Public Distribution System." PhD dissertation, London School of Economics and Political Science (LSE).

Masiero, Silvia. 2015. "Redesigning the Indian Food Security System Through e-Governance: The case of Kerala." World Development 67:126-37.

Masiero, Silvia, and Amit Prakash. 2015. "The Politics of Anti-poverty Artefacts: Lessons from the Computerization of the Food Security System in Karnataka." Presented at the Seventh International Conference on Information and Communication Technologies and Development, Singapore.

Masiero, Silvia. 2017. "Digital Governance and the Reconstruction of the Indian Anti-poverty System." Oxford Development Studies 45(4):393-408.

Masiero, Silvia. 2018. "Explaining Trust in Large Biometric Infrastructures: A Critical Realist Case Study of India's Aadhaar Project." Electronic Journal of Information Systems in Developing Countries 84(6):1-15.

Masiero, Silvia, and Soumyo Das. 2019. "Datafying Anti-poverty Programmes: Implications for Data Justice." Information, Communications and Society 22(7):916-33.

Mooij, Jos. 1998. "Food Policy and Politics: The Political Economy of the Public Distribution System in India." Journal of Peasant Studies 25(2):77-101.

Nair, Vijayanka. 2019. "Governing India in Cybertime: Biometric IDs, Start-Ups and the Temporalised State." South Asia: Journal of South Asian Studies 42(3):1-18.

Nilekani, Nandan, and Viral Shah. 2016. Rebooting India: Realizing a Billion Aspirations. London: Penguin UK. 
Prakash, Amit, and Silvia Masiero. 2015. "Does Computerization Reduce PDS Leakage? Lessons from Karnataka." Economic and Political Weekly 50(50):77-81.

Radhakrishna, Rokkam, and K. Subbarao. 1997. India's Public Distribution System: A National and International Perspective. Washington DC: World Bank Publications.

Radhakrishna, Rokkam. 1996. "Food Trends, Public Distribution System and Food Security Concerns.” Indian Journal of Agricultural Economics 51(1):168-183.

Rajan, Prasanth, Shweta Chopra, A. K. Somasekhar, and Chad Laux. 2016. "Designing for Food Security: Portability and the Expansion of User Freedoms Through the COREPDS in Chhattisgarh, India." Information Technologies and International Development 12(3):1-18.

Ramanathan, Usha. 2014. "Biometrics Use for Social Protection Programmes in India Violating Human Rights of the Poor." United Nations Research Institute for Social Development. Retrieved November 18, 2019 (http://www.unrisd.org/sp-hr-ramanathan).

Ramaswami, Bharat, and Pulapre Balakrishnan. 2002. "Food Prices and the Efficiency of Public Intervention: The Case of the Public Distribution System in India." Food Policy 27(5):419-36.

Rao, Ursula, and Vijayanka Nair. 2019. “Aadhaar: Governing with Biometrics.” South Asia: Journal of South Asian Studies 42(3):469-81.

Rao, Ursula. 2019. "Population Meets Database: Aligning Personal, Documentary and Digital Identity in Aadhaar-Enabled India." South Asia: Journal of South Asian Studies 42(3):1-17.

Roy, Tirthankar. 2016. “Were Indian Famines ‘Natural' Or ‘Manmade'?” LSE Economic History Working Paper 243:5.

Saini, Shweta, Sameedh Sharma, Ashok Gulati, Siraj Hussain, and Joachim von Braun. 2017. “ Indian Food and Welfare Schemes: Scope for Digitisation towards Cash Transfers.” ZEF Discussion Papers on Development Policy no. 241.

Sen, Amartya. 1981. Poverty and Famines: An Essay on Entitlement and Deprivation. Oxford: Clarendon Press.

Sen, Amartya, and Himanshu. 2004. "Poverty and Inequality in India: I." Economic and Political Weekly 39(38):4247-63.

Sen, Amartya, and Himanshu. 2011. “Why Not a Universal Food Security Legislation?” Economic and Political Weekly 46(12):38-47.

Shagun, K., and Aditi, A. 2016. "Even in Delhi, Basing PDS on Aadhaar is Denying Many the Right to Food." The Wire. Retrieved on November 18, 2019 (https://thewire.in/rights/right-to-foodhow-aadhaar-in-pds-is-denying-rights).

Singh, Ranjit. 2019. “Give Me a Database and I Will Raise the Nation-State.” South Asia: Journal of South Asian Studies 42(3):1-18.

Solanki, Aakash. 2019. "Management of Performance and Performance of Management: Getting to Work on Time in the Indian Bureaucracy." South Asia: Journal of South Asian Studies 42(3):118.

Srinivasan, Janaki, and Aditya Johri. 2013. "Creating Machine Readable Men: Legitimizing the " Aadhaar' Mega e-Infrastructure Project in India." Proceedings of Sixth International Conference on Information and Communication Technologies and Development: Full Papers-Volume 1. Cape Town: ACM. 
Sundaram, K., and Suresh D. Tendulkar. 2003. "Poverty in India in the 1990s: Revised Results for all-India and 15 Major States for 1993-94." Economic and Political Weekly 38(46):4865-72.

Suryanarayana, M.H. 1995. "PDS: Beyond Implicit Subsidy and Urban Bias-The Indian Experience.” Food Policy 20(4):259-78.

Svedberg, Peter. 2012. "Reforming or Replacing the Public Distribution System with Cash Transfers?" Economic and Political Weekly 47(7):53-62.

Swaminathan, Madhura. 2002. "Excluding the Needy: The Public Provisioning of Food in India." Social Scientist 30(3):34-58.

Swaminathan, Madhura. 2008. "Programmes to Protect the Hungry: Lessons from India." United Nations Department for Economics and Social Affairs. Working Paper No.70.

Taylor, Linnet. 2017. "What is Data Justice? The Case for Connecting Digital Rights and Freedoms Globally." Big Data and Society 4(2):1-14.

Tritah, Ahmed. 2003. "The Public Distribution System in India: Counting the Poor from Making the Poor Count." Groupe de Recherche en Economie Mathématique et Quantitative (GREMAQ), Université des Sciences Sociales, Toulouse.

Umali-Deininger, Dina L., and Klaus Deininger. 2001. “Towards Greater Food Security for India's Poor: Balancing Government Intervention and Private Competition. Agricultural Economies."

25(2-3):321-35.

Walsham, Geoff. 2006. “Doing Interpretive Research.” European Journal of Information Systems 15(3): 320-30.

Young, Stephen. 2010. Gender, Mobility and the Financialisation of Development. Geopolitics 15(3): 606-27.

\section{NOTES}

1. Sections of this manuscript have been adapted from my unpublished doctoral dissertation (Masiero 2014).

2. In this paper I refer to the PDS as a food security program because, although non-food items (e.g. kerosene) are also subsidised under the program, the scheme has the primary purpose of guaranteeing adequate nutrition to all Indian citizens. "Foodgrains"-primarily rice and wheatis the staple commodity in the scheme, and the term is often used to refer to PDS subsidised commodities at large.

3. Other scholars (Deaton 2003; Sundaram and Tendulkar 2003) claim that poverty decline in the 1990s has proceeded in line with earlier trends. This is based on controversy over different interpretations of data from the 61st round of the National Sample Survey (NSS).

4. The literature ascribes famines in colonial India to a combination of natural causes, such as mismatches between demand and supply induced primarily by crop failures, and man-made causes, notably political action that has adverse effects on redistribution (Roy 2016:2). See Bhatia (1991) for an in-depth historiography of famines in precolonial and colonial times and Roy (2016) for a review of theories regarding their relative causes.

5. The existence of the urban bias is, however, questioned by several studies (e.g. Dev and Suryanarayana 1991; Suryanarayana 1995) on the grounds that different measurements lead to different distributional outcomes.

6. Retrieved November 15, 2019 (https://uidai.gov.in/about-uidai.html).

7. Retrieved November 15, 2019 (https://uidai.gov.in/images/state-wise-aadhaar-saturation.pdf). 
8. Retrieved November 18, 2019 (http://www.livemint.com/Politics/BfeNi5AreTn1cJ8ROIzxXM/ NDA-kicks-off-PDS-reforms.html).

9. Retrieved November 18, 2019 (https://scroll.in/article/805909/in-rajasthan-there-is-unrestat-the-ration-shop-because-of-error-ridden-aadhaar).

10. This might, however, be a consequence of the general good functioning of PDS in Karnataka, which performs better than most Indian states on PDS offtake (Khera 2011b). While we have not surveyed states which lag behind on PDS performance, it is possible that such states may display lower reliance of users on ration shops.

\section{ABSTRACTS}

This paper reflects on the author's nine-year research on the transformation of India's Public Distribution System (PDS) enacted through digital technologies first and, more recently, through Aadhaar's biometric infrastructure. Based on the experiences of two states, Kerala and Karnataka, which adopted biometric identification in their ration shops, the paper illustrates the effects of the transition to an Aadhaar-based PDS, on both program governance and recipients' entitlements. It argues that, while designed with the objective of combating the rice mafia resulting in foodgrain diversion, a biometric PDS does not prevent the exclusion errors pervading the program, and supports the transition to a cash transfer system whose developmental outcomes are still uncertain. Contributing to the debate on coded citizenship in South Asia, this paper reflects on the transformative power that biometric infrastructures yield over food security schemes, and considers different ways a computerized PDS may be tailored for the inclusion of vulnerable groups.

\section{INDEX}

Keywords: biometric infrastructures, Public Distribution System, food security, anti-poverty policy, Aadhaar, India

\section{AUTHOR}

\section{SILVIA MASIERO}

Department of Informatics, University of Oslo 